\title{
MARCADORES MOLECULARES MICROSSATÉLITES NAAVALIAÇÃO DE SEMENTES DE SOJA COM VARIAÇÃO NA COLORAÇÃO DO HILO ${ }^{1}$
}

\author{
MARCELO RABEL ${ }^{2}$, ELISA SERRA NEGRA VIEIRA ${ }^{3}$, UBIRACI GOMES DE PAULA LANA ${ }^{4}$, \\ EDILSON PAIVA ${ }^{5}$, MARGARETE APARECIDA SELLA SEHNEM ${ }^{6}$, IVAN SCHUSTER ${ }^{3}$
}

\begin{abstract}
RESUMO - Marcadores microssatélite têm sido utilizados na determinação da pureza genética em programas de melhoramento e de produção de sementes, visando garantir a qualidade genética das sementes. Objetivou-se neste trabalho demonstrar, com auxílio de marcadores moleculares microssatélites, que variações na coloração do hilo em sementes de soja, muitas vezes não constituem variação genética. Foram avaliadas sementes de soja da cultivar CD 222 que apresenta sementes com hilo preto, e de duas linhagens (CD 02RV-8444 e CD 01RV-7618), as quais apresentam sementes com hilo marrom. As sementes com variações na coloração e tonalidade do hilo encontradas em cada genótipo foram separadas visualmente em grupos. $\mathrm{O}$ DNA de cada semente foi extraído e analisado com marcadores microssatélites em "bulks" contendo DNA de cinco sementes. As variações encontradas na coloração do hilo da cultivar CD 222 e da linhagem CD 02RV-8444 não foram devidas à variação genética, considerando 16 locos microssatélites. Para a linhagem CD 01RV-7618, os bulks de sementes com hilo marrom pigmentado de preto (B1), com hilo marrom mais intenso (B2) e intermediário (B3), foram considerados iguais. Para esta mesma linhagem foi detectada diferença no bulk de sementes com hilo marrom menos intenso (B4), com o primer Satt 070. Duas sementes deste bulk apresentaram o mesmo padrão molecular observado para os outros bulks, no mesmo loco. As demais sementes foram consideradas misturas. A utilização de marcadores microssatélites demonstra que variações na cor ou tonalidade do hilo da soja nem sempre correspondem à variação genética.
\end{abstract}

Termos para indexação: Glycine max, cor do hilo, pureza genética, SSR.

\section{MICROSATELLITE MOLECULAR MARKERS IN THE EVALUATION OF SOYBEAN SEEDS WITH VARIATION IN HILUM COLOR}

\begin{abstract}
Microsatellite markers have been used in determining genetic purity in breeding programs and seed production to ensure seed genetic quality. The objective of this study was to demonstrate, with the aid of microsatellite molecular markers, that changes in the hilum color of soybean seeds are not necessarily related to genetic variation. Seeds of the CD 222 cultivar, showing a black hilum, and of two breeding lines (CD 02RV-8444 and CD 01RV-7618) showing a brown hilum, were evaluated. Seeds with color variation in the hilum of each genotype were visually
\end{abstract}

\footnotetext{
${ }^{1}$ Submetido em 20/08/2009. Aceito para publicação em 11/03/2010.

${ }^{2}$ Biólogo, MSc., Bolsista do Núcleo de Biologia Aplicada da Embrapa Milho e Sorgo, CP 151, CEP 37202-098, Sete Lagoas, MG, marcelorabel@ gmail.com.

${ }^{3}$ Eng. Agr. Dr(a)., Pesquisador do Departamento de Biotecnologia da Cooperativa Central de Pesquisa Agrícola - Coodetec. Cx. Postal 301, CEP: 85813-450. Cascavel, PR, ivan@coodetec.com.br, esnegra@coodetec.com. br.

${ }^{4}$ Químico, MSc., Analista do Núcleo de Biologia Aplicada da Embrapa
}

Milho e Sorgo. Cx. Postal 151, CEP: 37702-098. Sete Lagoas, MG, ubiraci@cnpms.embrapa.br.

${ }^{5}$ Eng. Agr. PhD., Pesquisador do Núcleo de Biologia Aplicada da Embrapa Milho e Sorgo, CP 151, CEP 37702-098, Sete Lagoas, MG, edilson@ cnpms.embrapa.br.

${ }^{6}$ Analista de sementes responsável pelo Laboratório de Controle de Qualidade da Coodetec, CP 301, CEP 85813-450, Cascavel, PR, margasella@coodetec.com.br. 
separated into groups. The DNA of each seed was extracted and analyzed with microsatellite markers in DNA "bulks" of five seeds. The color variation found in the hilum of CD 222 and CD 02RV-8444 seeds did not show any genetic variation based on 16 microsatellite loci. For the CD 01RV-7618 line, the bulk of seeds with a brown-black hilum (B1), with an intense brown hilum (B2) and with an intermediary brown hilum (B3) showed the same molecular pattern. The seeds from the same line with a faint brown hilum (B4) showed a difference with the locus Satt070. Of the five seeds of this bulk, two showed the same molecular pattern of the other bulks at the same locus. The remaining seeds were considered mixtures. The use of microsatellite markers demonstrated that variations in color or tone of the soybean hilum do not always correspond to genetic variation.

Index terms: Glycine max, hilum color, genetic purity, SSR.

\section{INTRODUÇÃO}

Na semente está armazenada toda tecnologia obtida com o melhoramento de plantas. Por este motivo, esta deve ter alta qualidade fisiológica e ser geneticamente pura. Em soja, uma das principais características utilizadas pelos melhoristas para descrever uma cultivar é a cor do hilo da semente. Essa característica também é bastante importante nos laboratórios de análise de sementes, para diferenciar cultivares e detectar misturas varietais durante o processo de certificação. Além da cor do hilo, outras características estão associadas à semente, tais como: tamanho, formato, coloração e aspecto do tegumento e formato do hilo (Moreira et al., 1999).

É comum observar variações na cor do hilo em sementes de soja em função dos efeitos ambientais, como a ocorrência de veranicos e de altas temperaturas durante a fase de desenvolvimento das sementes. Nestas condições, cultivares de soja podem produzir sementes com coloração do hilo diferente do padrão, sem apresentar variação genética (Moreira et al., 1999). Camps et al. (1994) observaram diferenças de tonalidade na cor do hilo entre sementes de soja da mesma cultivar, semeadas tanto na mesma época como em épocas diferentes. Esses autores também constataram que em algumas cultivares a cor do hilo variava até entre sementes da mesma planta. Em condições controladas, França-Neto et al. (2002) observaram estas mesmas variações na cor do hilo, sendo mais frequentemente encontradas no terço superior das plantas. Esses resultados foram semelhantes aos obtidos por Moreira et al. (1999) em condições de campo.

O controle genético da formação de pigmentos da cor do hilo em soja é uma característica qualitativa relativamente simples, embora envolva interações alélicas com genes que controlam as cores da pubescência e da flor. Há uma série de alelos que controla a formação e a distribuição de pigmentos na semente. Plantas portadoras do alelo $(I)$ tendem a produzir sementes com coloração do hilo mais clara. Assim, hilos de coloração preta ou preta imperfeita tendem a variar para coloração cinza e hilos de coloração marrom tendem a ser amarelos (Sediyama et al., 1981; Destro et al., 1990).

Os descritores morfológicos são os mais recomendados para análises de pureza de sementes, mas apresentam algumas desvantagens, como a influência do ambiente, além de requererem tempo e espaço para serem avaliados. Além disso, a soja é uma cultura de base genética estreita, o que dificulta ainda mais a separação de cultivares por meio de tais descritores (Vieira, 2004).

Quando uma cultivar apresenta diferenças em um descritor da semente, nem sempre essas diferenças são genéticas, ou seja, se tratam de mistura varietal. Muitas vezes as sementes estão fora do padrão da cultivar devido às influências do ambiente. Nessas circunstâncias, lotes de sementes de elevado padrão correm o risco de serem descartados, causando prejuízos para os produtores de sementes. Algumas vezes, por meio da análise visual, não é possível afirmar se tais variações ocorridas na cor do hilo são em função do ambiente ou são misturas encontradas na amostra. Para esclarecer questões como essa, os marcadores moleculares do tipo microssatélite (SSR) vêm se destacando como importante tecnologia no controle de qualidade em diversas empresas (Schuster et al., 2006).

Testes de pureza genética de sementes de soja com marcadores moleculares podem ser realizados com a formação de grupos de sementes chamados de "bulk", como sugerido por Schuster et al. (2004). A análise em "bulks" fornece resultados com maior rapidez e com a mesma precisão da análise individual das sementes, além de reduzir tempo e custos. Marcadores, microssatélites por serem codominantes, permitem identificar se existe variação genética entre as sementes que constituem o mesmo "bulk". 
O objetivo deste trabalho foi demonstrar, com auxílio de marcadores moleculares microssatélites, que variações na coloração do hilo em sementes de soja, muitas vezes, não constituem variação genética.

\section{MATERIAL E MÉTODOS}

O trabalho foi conduzido na Cooperativa Central de Pesquisa Agrícola - Coodetec, localizada na rodovia BR 467, km 98, Cascavel - PR, nos Laboratórios de Controle de Qualidade de Sementes e de Biotecnologia.

\section{Obtenção do material genético e separação visual das sementes}

Foram utilizadas sementes das linhagens CD 02RV8444 e CD 01RV-7618 e da cultivar CD 222. As sementes das linhagens foram obtidas do programa de melhoramento genético de soja da Coodetec. As sementes da cultivar CD 222 foram obtidas a partir de amostras de lotes de sementes certificadas submetidas à análise no Laboratório de Controle de Qualidade de Sementes da Coodetec.

As sementes da linhagem CD 02RV-8444 foram produzidas na safra 2003/2004 e da linhagem CD 01RV7618 na safra 2004/2005, ambas em Primavera do Leste MT. Já as sementes da cultivar CD 222 foram produzidas na safra 2004/2005, em São Miguel do Passa Quatro - GO.

As sementes de cada linhagem e da cultivar foram separadas por meio da análise visual, de acordo com diferenças observadas na cor e tonalidade do hilo. A cultivar CD 222 apresenta sementes com hilo preto e as linhagens CD 02RV-8444 e CD 01RV-7618 sementes com hilo marrom.

\section{Extração do DNA genômico das sementes}

$\mathrm{O}$ isolamento do DNA genômico de cada genótipo de soja foi realizado utilizando-se o protocolo adaptado de McDonald et al. (1994). Inicialmente, $50 \mathrm{mg}$ de sementes raspadas foram transferidas para microtubos de $1,5 \mathrm{~mL}$, contendo uma esfera de vidro de $3 \mathrm{~mm}$ de diâmetro. Posteriormente, foram adicionados $500 \mu \mathrm{L}$ de tampão de extração [200 mM de Tris- $\mathrm{HCl} \mathrm{pH}$ 7,5; $288 \mathrm{mM}$ de $\mathrm{NaCl}$; $25 \mathrm{mM}$ de EDTA pH 8,0 e $0,5 \%$ (m/v) SDS]. Os microtubos foram submetidos à agitação rigorosa em agitador Grinder por 1 minuto. A seguir, foram adicionados novamente 500 $\mu \mathrm{L}$ de tampão de extração, sendo as amostras submetidas à agitação em vortex por 30 segundos. As amostras foram centrifugadas a $16.000 \mathrm{x}$ g por 10 minutos e o sobrenadante transferido para novos microtubos. As proteínas foram removidas adicionando-se $10 \mu \mathrm{L}$ de Proteinase $\mathrm{K}(10 \mathrm{mg} /$ $\mathrm{mL}$ ), sendo a mistura incubada em banho-maria a $37^{\circ} \mathrm{C}$ por 30 minutos. Foram adicionados $500 \mu \mathrm{L}$ de isopropanol gelado $\left(-20^{\circ} \mathrm{C}\right)$ e as amostras foram homogeneizadas. Após dois minutos os microtubos foram centrifugados por 10 minutos a $16.000 \mathrm{x} \mathrm{g}$. O sobrenadante foi descartado e o precipitado formado foi seco por 15 minutos à temperatura ambiente.

$\mathrm{O}$ precipitado foi ressuspendido em $300 \mu \mathrm{L}$ de $\mathrm{TE}$ (10 mM Tris-HCl pH 7,5; 1 mM EDTA pH 8,0), contendo $40 \mu \mathrm{g} / \mathrm{mL}$ de RNAse A para eliminação do RNA. Os tubos foram colocados novamente em banho-maria a $37^{\circ} \mathrm{C}$ por 30 minutos, e em seguida foi adicionado $500 \mu \mathrm{L}$ de isopropanol gelado aguardando-se 2 minutos para precipitação do DNA. Os microtubos foram centrifugados por 15 minutos a 16.000 $\mathrm{x}$ g. O sobrenadante foi descartado e o precipitado formado foi seco por 15 minutos à temperatura ambiente. O pellet foi ressuspendido em $300 \mu \mathrm{L}$ de TE.

As amostras de DNA foram quantificadas em espectrofotômetro a $260 \mathrm{~nm}$ e a qualidade avaliada pela relação entre a absorbância a 260 e $280 \mathrm{~nm}$.

\section{Construção dos "bulks" de DNA e amplificação dos microssatélites}

Para cada grupo de sementes foram construídos "bulks" formados pela mistura de $40 \mu \mathrm{L}$ de DNA de cinco sementes na concentração de $10 \mathrm{ng} / \mu \mathrm{L}$. A formação de "bulks" com cinco amostras foi recomendada por Schuster et al. (2004) como sendo eficiente na detecção de variações em géis de agarose.

As reações de amplificação foram realizadas em um volume de $20 \mu \mathrm{L}$, contendo $20 \mathrm{mM}$ de Tris- $\mathrm{HCl}(\mathrm{pH} \mathrm{8,3);50}$ $\mathrm{mMKCl} ; 3 \mathrm{mM} \mathrm{MgCl}_{2} ; 250 \mu \mathrm{M}$ de cada desoxiribonucleotídeo (dATP, dTTP, dGTP e dCTP); 0,2 $\mu \mathrm{M}$ de cada "primer", uma unidade da enzima Taq DNA polimerase e $30 \mathrm{ng}$ de DNA molde.

As reações de microssatélites foram realizadas em termociclador Thermo Hybaid (Ashford, Middlesex, Reino Unido) programado para um estágio inicial de três minutos a $94{ }^{\circ} \mathrm{C}$, seguido de 35 ciclos de 30 segundos a $94{ }^{\circ} \mathrm{C}, 30$ segundos a $56^{\circ} \mathrm{C}$ e 45 segundos a $72{ }^{\circ} \mathrm{C}$ e uma etapa final de extensão de 10 minutos a $72{ }^{\circ} \mathrm{C}$. Os fragmentos amplificados foram separados por eletroforese em gel de agarose e sinergel a $3 \%(\mathrm{~m} / \mathrm{v})$ contendo brometo de etídio $(70 \mu \mathrm{g} / \mathrm{mL})$ e em gel de poliacrilamida $10 \%(\mathrm{~m} / \mathrm{v})$. Após a eletroforese, os géis de agarose foram visualizados sob luz ultravioleta e fotografados no equipamento Lourmat (Marne-la-Vallée, Cedex 1, France). Os géis de poliacrilamida foram corados com nitrato de prata 0,2\% (m/v) segundo Sanguinetti et al. (1994).

As análises foram realizadas com 16 locos microssatélites (Tabela 1), escolhidos de acordo com a localização nos cromossomos, de forma a garantir a representatividade da maior parte do genoma da soja. 
TABELA 1. Relação dos primers SSR utilizados.

\begin{tabular}{lcll}
\hline Primers SSR & $\begin{array}{c}\text { Grupo de } \\
\text { ligação }\end{array}$ & \multicolumn{1}{c}{ Sequência 5'-3' senso } & \multicolumn{1}{c}{ Sequência 5'-3' anti-senso } \\
\hline Satt591 & A1 & GCGCGACCTTAATGATA & GCGCCCAAAGCTTAAAATTTAATA \\
Satt480 & A2 & CGTCCCACCATCACAAGCGATCA & $\begin{array}{l}\text { GCGGTTAGCTTCGGTTATTAAT } \\
\text { Satt } 270\end{array}$ \\
Satt070 & B1 & TGTGATGCCCCTTTTCT & GCGCAGTGCATGGTTTTCTCA \\
Satt399 & C1 & AAGCCAACCTTATAATTCTTTCAT & ATATGGGCTTACTTACCCATCATAGA \\
Satt450 & C2 & GGATGTTTGAGACGT GACATCTTGAT & GGATTAATAAAATGTCATGCCTTAGT \\
Sat_413 & Dla & GCGCTCCCTTCTTTTCCACTGAATTGA & GCGTTTTCTCTCGGTTCTCTCTTCTTATTA \\
Satt542 & Dlb & CACCAGCACAGAACAATCATTT & CACGGTCTAACCTTTCCTTCTA \\
Satt458 & D2 & TTGGGTTGACCGTGAGAGGGAGAA & GCGAACCACAAACAACAATCTTCA \\
Satt263 & E & CACCCAATCATG ATAGCATTTTAT & CTCATGGAATTGTCTTTCAGTTTC \\
Satt193 & F & GCGTTTCGATAAAAATGTTACACCTC & TGTTCGCATTATTGATCAAAAAT \\
Satt356 & G & CATGCCTGGTCCATTTTG & TCAAGCCACGATAACAGTA \\
Satt353 & H & CATACACGCATTGCCTTTCCTGAA & GCGAATGGGAATGCCTTCTTATTCTA \\
Satt451 & I & GCGCAATTAAAAGGATAACTTATATC & CCCCTCTTTGGCCCTCACACCTTCTC \\
Satt406 & J & GCGTGAGCATTTTTGTTT & TGACGGGTTTAATAGCAT \\
Satt178 & K & GGGAAAATTCTTTTCATATAGATG & GGGGTTGAGATATTTTGTTCATAC \\
\hline
\end{tabular}

\section{RESULTADOS E DISCUSSÃO}

A partir da análise visual com base na coloração do hilo das sementes da cultivar CD 222 foram separados dois grupos, formados por cinco sementes cada. Um grupo se constituiu de sementes com hilo marrom claro e o outro de sementes com hilo preto (padrão da cultivar). As diferenças visuais observadas na coloração do hilo da cultivar CD 222 variaram do preto para marrom (Figura 1A), não implicando em diferenças genéticas na avaliação dos 16 locos microssatélites. A Figura 1B ilustra o resultado da amplificação dos dois "bulks" de DNA com os marcadores Satt070 e Satt270. Os dois grupos de sementes da cultivar, além de não apresentarem diferenças moleculares entre si, não apresentaram diferenças moleculares entre as sementes que compõe os "bulks".

As sementes da linhagem CD 02RV-8444 foram separadas em três grupos, constituídos por cinco sementes cada. Os três grupos apresentaram sementes com hilo de cor marrom, variando do marrom com tonalidade mais intensa até a cor marrom menos intensa (Figura 2A). Para essa linhagem também não foram constatadas diferenças genéticas para os 16 locos microssatélites. Na Figura 2B está ilustrado o resultado da análise molecular com os locos microssatélites Satt070 e Satt451, demonstrando que não há variação genética para estes marcadores.
As variações observadas na cor do hilo apresentadas na cultivar CD 222 e na linhagem CD 02RV-8444 devem ser atribuídas a influências de fatores ambientais durante o processo de formação das sementes. A cultivar CD 222 foi produzida no estado de Goiás e as sementes da linhagem CD 02RV-8444 foram produzidas no estado de Mato Grosso. Nessas regiões a ocorrência de altas temperaturas é frequente. Moreira et al. (1999) observaram variações semelhantes em duas cultivares de soja produzidas em regiões com veranicos e altas temperaturas durante a fase de formação das sementes.

As sementes da linhagem CD 01RV-7618, que deveriam possuir hilo marrom, foram separadas em quatro grupos de acordo com o tipo de hilo apresentado, sendo observadas variações na cor e na tonalidade entre esses grupos. No grupo B1 as sementes apresentaram hilo marrom com pigmentação preta, nos grupos de sementes B2, B3 e B4 a coloração variou de marrom mais forte a mais claro (Figura 3A). Essa linhagem também foi produzida no estado de Mato Grosso e provavelmente as diferenças observadas na cor do hilo são devidas a altas temperaturas na fase de formação das sementes. Os grupos de sementes B1, B2 e B3 não apresentaram diferenças genéticas para os 16 locos microssatélites (Figura 3B). No entanto, para o grupo B4 foi detectado, no loco microssatélite Satt070, a presença de dois alelos, indicando haver variação genética entre as sementes 
do "bulk" (Figura 3B). A análise individual das sementes confirmou a variação observada no "bulk" 4 (Figura 3C). Nesta análise foi utilizado o "bulk" 1 (B1) como controle, pois este não apresentou variação. As sementes 1 e 2 apresentaram o mesmo perfil molecular do "bulk" controle B1, se tratando de sementes da linhagem CD 01RV-7618. As sementes 3, 4 e 5 apresentaram um alelo que não corresponde ao padrão da linhagem, sendo consideradas misturas varietais. Mesmo não havendo diferenças na coloração do hilo das sementes que compõe o grupo 4 (B4), foi detectada diferença genética utilizando o loco microssatélite Satt070 em três sementes deste grupo. Assim, mesmo entre as sementes com cor do hilo uniforme pode existir contaminação genética detectada por meio de locos SSR. O loco Satt070 apresentou um elevado valor de informatividade $(0,74)$ em trabalho anteriormente realizado para a caracterização de um conjunto de 53 cultivares de soja por meio de marcadores microssatélite em géis de agarose, o que indica que este loco microssatélite é eficiente na detecção de diferenças (Vieira et al., 2009).
A

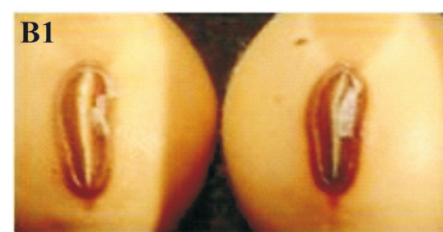

B2
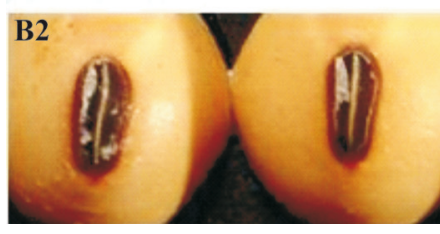
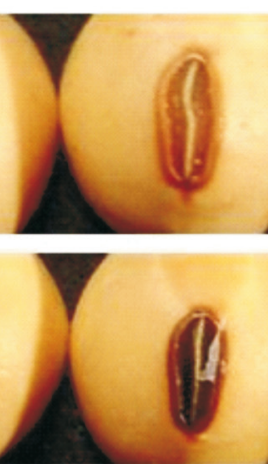
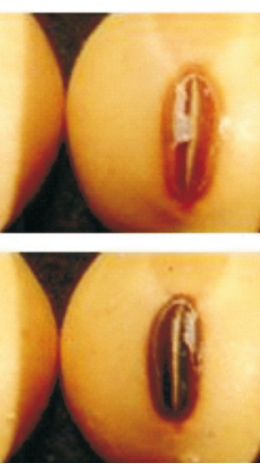
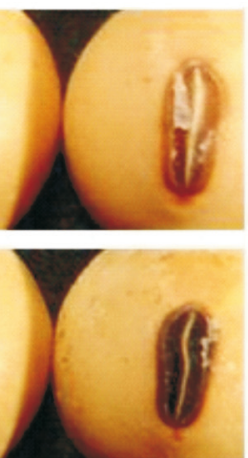

B

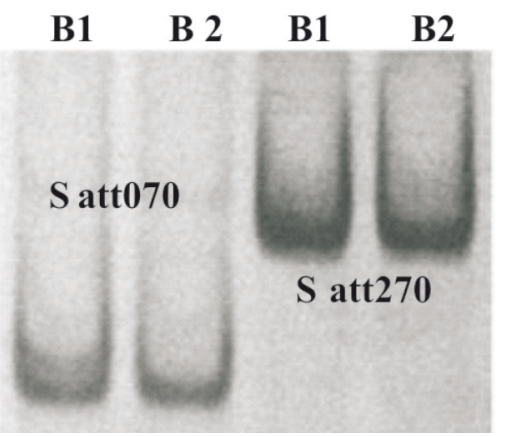

FIGURA 1. Análise da pureza genética em sementes de soja da cultivar CD 222 com variação na cor do hilo. A) B1: sementes com hilo marrom claro; B2: sementes com (hilo preto padrão da cultivar). B) Padrões moleculares dos "bulks" obtidos com os primers Satt070 e Satt270.

A

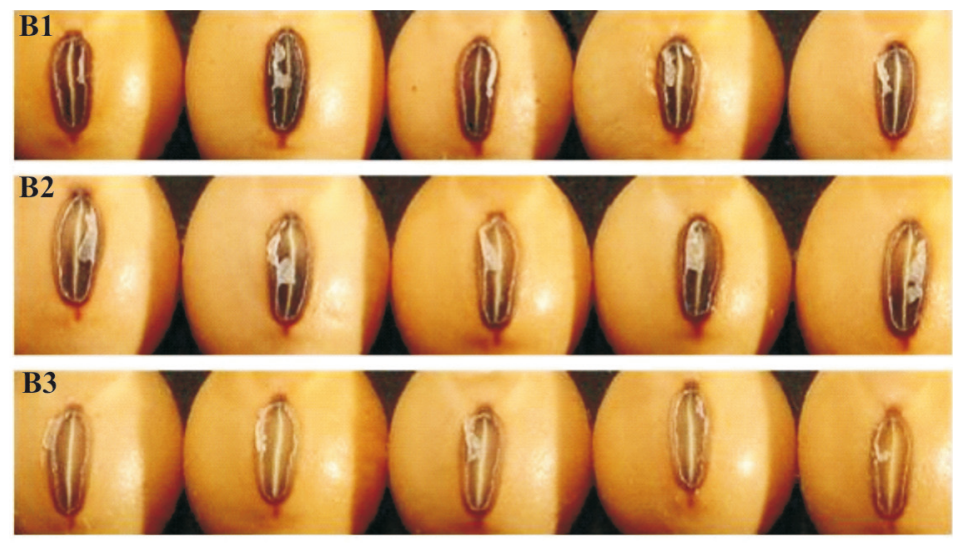

B

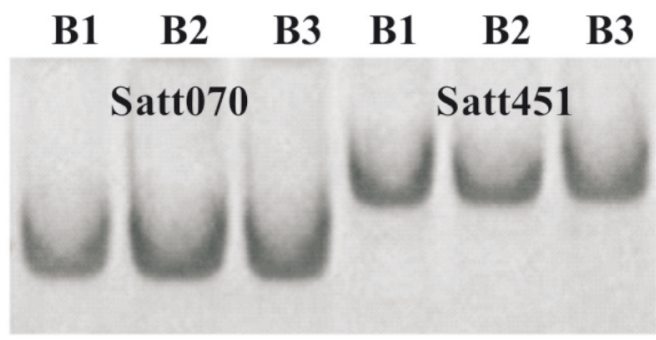

FIGURA 2. Análise da pureza genética em sementes de soja da linhagem CD 02RV-8444 com variação na cor do hilo. A) B1: sementes com hilo marrom mais intenso; B2: sementes com hilo marrom intermediário; B3: sementes com hilo marrom menos intenso. B) Padrões moleculares dos "bulks" obtidos com os primers Satt070 e Satt451. 
A
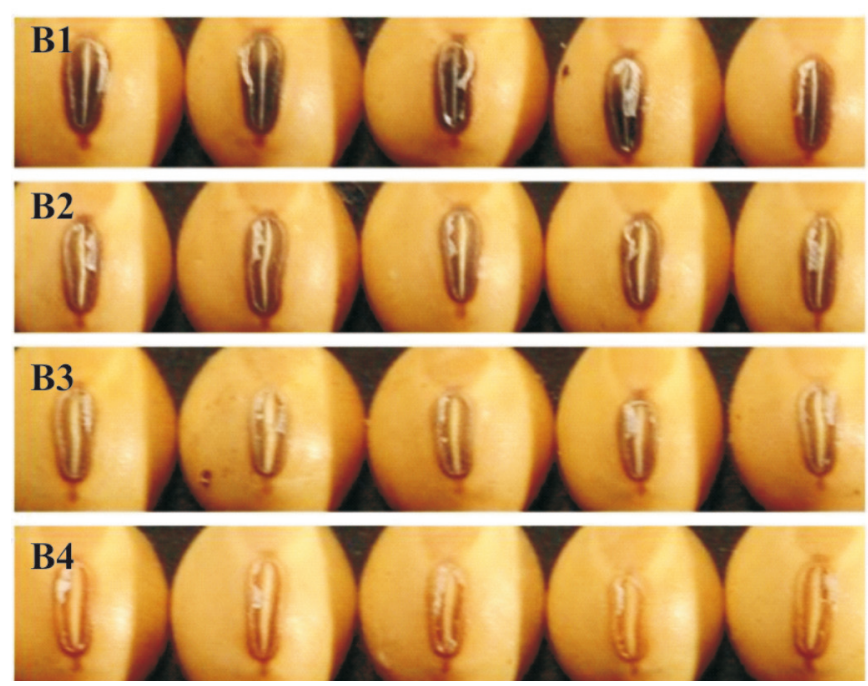

B

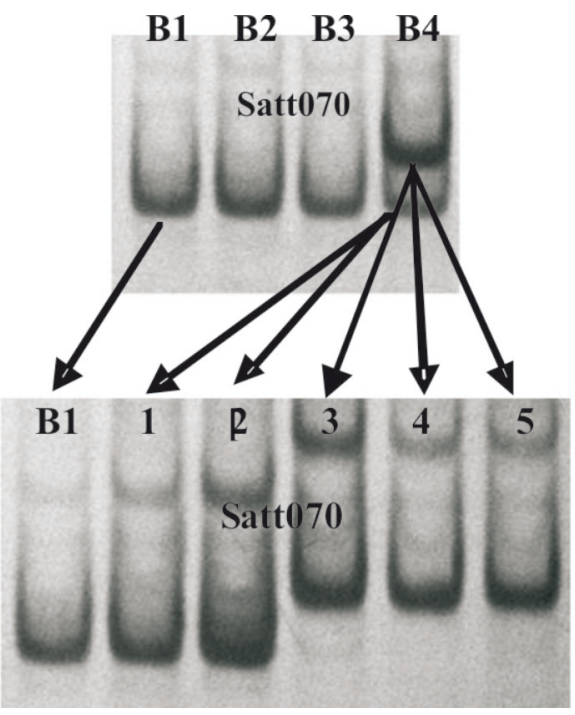

FIGURA 3. Análise da pureza genética em sementes de soja da linhagem CD 01RV-7618 com variação na cor do hilo. A) B1: sementes com hilo marrom com pigmentação preta; B2: sementes com hilo marrom intenso; B3: sementes com hilo marrom intermediário; B4: sementes com hilo marrom menos intenso. B) Padrão molecular dos "bulks" obtido com o primer Satt070. C) Padrão das sementes individuais do "bulk" 4 obtido com o primer Satt070.

Como pode ser observado no padrão molecular do "bulk" 4 da linhagem CD 01RV-7618, o alelo que corresponde ao padrão da linhagem apresentou menor intensidade no gel do que o alelo das sementes contaminantes, pois do total de cinco sementes que constituíam o "bulk", três sementes foram consideradas contaminantes (Figura 3b). Deve ser ressaltado que este tipo de análise não permite quantificar o nível de contaminação e, dessa maneira, a observação de variação na intensidade dos fragmentos permite apenas visualizar o menor ou maior grau de contaminação (Ramos et al., 2006).

A análise molecular em "bulks" foi eficiente na avaliação de sementes com variação na cor do hilo e também para detectar misturas varietais, como já relatado por Schuster et al. (2004). A utilização de "bulks" para cultivares de espécies alógamas é também recomendada no monitoramento da pureza genética das linhagens parentais (Ramos et al., 2006). A mesma estratégia pode ser utilizada também para a certificação da pureza genética de lotes de híbridos, levandose em consideração a natureza codominante dos marcadores microssatélite. Neste último caso, como na maioria das vezes não se conhece as possíveis misturas do lote, deve-se adotar certos critérios na escolha dos marcadores a serem testados. Primers monomórficos entre as linhagens parentais devem ser utilizados. Assim, a detecção de mais de um alelo indicaria a ocorrência de mistura varietal. Além disso, nestes casos, a análise de sementes individuais é recomendada (Salgado, 2001; Schuster et al, 2006).

Se as análises não tivessem sido realizadas em "bulks", seriam necessárias 720 reações, considerando as 45 sementes e os 16 locos microssatélites utilizados neste trabalho. Como as análises foram realizadas em "bulks", foram necessárias apenas 144 reações, o que diminui os custos e o tempo para realização das mesmas.

Como demonstrado no presente trabalho, a utilização de apenas descritores morfológicos como cor de hilo nos testes de pureza genética de sementes de soja, não é confiável, levando a aprovação ou condenação errônea de lotes de sementes. Sendo assim, a utilização de marcadores moleculares do tipo microssatélites, associados aos descritores morfológicos de sementes, torna-se uma ferramenta útil em casos de dúvidas no momento da análise de sementes. Além disso, quando os descritores morfológicos não são suficientes para a discriminação de genótipos de soja, o Serviço Nacional de Proteção de Cultivares (SNPC) tem aceitado dados moleculares.

\section{CONCLUSÕES}

Marcadores moleculares microssatélites são eficientes para avaliação de sementes de soja com variação na coloração 
do hilo e para detecção de misturas varietais.

As variações observadas na coloração do hilo nas amostras de sementes da cultivar CD 222 e da linhagem CD 02RV-8444 não são resultantes de variação genética.

Sementes da linhagem CD 01RV-7618 com hilo marrom menos intenso apresentam variação genética.

\section{REFERÊNCIAS}

CAMPS, G.; VERNETI, F.J.; AUGUSTIN, E.; IRIGON, D. Caracterização morfológica e eletroforética de 20 cultivares de soja. Revista Agropecuária Brasileira, v.29, n.11, p.1779-1787, 1994.

DESTRO, D.; SEDIYAMA, T.; GOMES, J.L.L. Genes qualitativos em soja: alguns comentários e listagem. Viçosa: Imprensa Universitária da UFV, 1990. 67p. (Cadernos Didáticos, 293).

FRANÇA-NETO, J.B.; MOREIRA, C.T; KRZYZANOWSKI, F.C.; COSTA, N.P.; SOUZA, P.I.M.; ALMEIDA, L.A.; HENNING, A.A. Variação da cor do hilo, em sementes de cultivares de soja, submetidas a diferentes condições de temperatura ambiente e umidade do solo. In: Congresso Brasileiro de Soja, 2., 2002, Foz do Iguaçu. Resumos... Londrina: Embrapa soja; Embrapa cerrados, 2002. p.366.

McDONALD, M.B.; ELLIOT, L.J.; SWEENEY, P.M. DNA extraction from dry seeds for RAPD analyses in varietal identification studies. Seeds Science \& Technology, v.22, p.171-176, 1994.

MOREIRA, C.T.; SOUZA, P.I.M.; FARIAS NETO, A.L.; ALMEIDA, L.A. Ocorrência de variações na coloração do hilo de sementes de cultivares de soja [Glycine max (L.) Merrill]. Planaltina: Embrapa Cerrados, 1999. 4p. (Embrapa Cerrados. Comunicado Técnico, 5).

RAMOS, N.P.; BRUNELLI, K.R.; CAMARGO, L.E.A.; MARCOS FILHO, J. Sensibilidade dos microssatélites para determinar a pureza varietal em sementes de milho. Revista Brasileira de Sementes, v.28, n.1, p.99-105, 2006.

SALGADO, K.C.C. Certificação da pureza genética em sementes híbridas de milho por meio de marcadores morfológicos e moleculares. 2001. 67f. Dissertação (Mestrado em Fitotecnia) - Universidade Federal de Lavras, Lavras, 2001.

SANGUINETTI, C.J.; NETO, E.D.; SIMPSON, A.J.G. Rapid silver staining and recovery of PCR products separated on polyacrylamide gels. BioTechniques, v.17, p.914-921, 1994.

SCHUSTER, I.; QUEIROZ, V.T.; TEIXEIRA, A.I.; BARROS, E.G.; MOREIRA, M.A. Determinação da pureza varietal de sementes de soja com auxílio de marcadores moleculares microssatélites. Pesquisa Agropecuária Brasileira, v.39, n.3, p.247-253, 2004.

SCHUSTER, I.; VIEIRA, E.S.N.; PADILHA, L. Marcadores moleculares no pós-melhoramento. In: BORÉM, A.; CAIXETA, E.T. Marcadores moleculares. Viçosa: Universidade Federal de Viçosa, 2006. p.205230 .

SEDIYAMA, T.; ALMEIDA, A.L.; MIYASAKA, S.; KIIHL, R.A.S. Genética e melhoramento. In: MIYASAKA, S.; MEDINA, J.C. (Ed.). A soja no Brasil. Campinas: Instituto de Tecnologia de Alimentos, 1981. p.209-226.

VIEIRA, E.S.N. Marcadores morfológicos, bioquímicos e moleculares na caracterização de cultivares de soja e café. 2004. 137f. Tese (Doutorado em Fitotecnia) - Universidade Federal de Lavras, Lavras, 2004.

VIEIRA, E.S.N.; SCHUSTER, I.; SILVA, R.B.; OLIVEIRA, M.A.R. Variabialidade genética em cultivares de soja obtida com marcadores microssatélites genotipados em géis de agarose. Pesquisa Agropecuária Brasileira, v.44, n.11, p.1460-1466. 2009. 